\section{The Future of the \\ Concert Review}

by Jennifer Bernard Merkowitz, Co-Editor

In our last issue (Winter 2006, p. 43), we published an article by Leigh Landy entitled "Why Haven't I Written about the Pieces Played at ICMC?" In his article, Landy questioned the usefulness of reviews of "one-off events." Many of the pieces performed at the ICMC are new works that are not easy to come by Generally, only the people who attended the concert have had the opportunity to hear them. Subsequent hearings - which are necessary to fully appreciate any type of music, and especially music that is presented at an ICMC-are difficult, if not impossible. Chances are that if you have been reading this issue of Array from the beginning, you have already complained that the pieces discussed in the reviews are either distant memories or completely unknown to you.

Landy also lamented the practice of what he terms "Mutual Back Patting" in many ICMC reviews. The author of the review engages in little more than technical explanations, polite encouragement, and deliberately vague language. Lacking is an actual assessment of the success of the work from an aesthetic standpoint.

I am happy to say that many of the reviews published in this issue do attempt to grapple with the issue of the composer's intent and a piece's ability to hit the mark. However, there still remains a fair bit of blow-by-blow commentary and program note paraphrasing that gets passed off as serious reviewing, and Array is not the only place that such reviews appear. This phenomenon is woefully present in many realms of the new music world. Are we afraid that being frank about our colleagues' work will hurt their self-esteem? Or are we afraid that someone else might look at our own work with a similarly critical eye? Are we - composers, performers, and engineers dedicated to the development, promotion and appreciation of computer music - doing ourselves any favors by not speaking our minds about what moves us? No, we are not.

Array is certainly not equipped to solve this entire crisis of reception on our own, but we'd like to attempt to make our own reviews more relevant to our readers. So how do we solve these problems? There are two main issues: the first is the problem of enabling repeat hearings, and the second is the lack of honest and intelligent debate. In his article, Landy wished to see "active musical debate (and distribution) replace the review until the status of appreciation has been improved." With the release of ICMA's new website, we hope to come closer to that goal.

Margaret Schedel, Toine Heuvelmans, Jeffrey Treviño and I (along with a few others) have been discussing the best way to use the website to enable a "hyper-print" version of Array to exist - one that, while not eschewing the "traditional" printed reviews, enables repeat listening of select pieces and the capacity to discuss them online. The role of the "reviewer," then would not be someone who jots down notes on his or her program booklet and types them up a week (or a month, or six months) later, but someone whose role is more like that of a moderator who leads a discussion board and summarizes the discussion afterward in printed format The printed review would contain a link to the discussion, enabling interested reader of Array to listen to the piece and contribute to further discussion. We could not do this, of course, without the permission of the artists involved; while some might be enthusiastic to distribute their piece to wider audience, others might be hesitant for any number of good reasons. This might be solved by adding a checkbox to future ICMC submission forms that lets artists choose whether they give ICMA the right to post their submitted piece on the website. Discussion could still take place about pieces without online documentation. If all goes well, we could extend the format to deal with other events posted by members on the website.

Before we roll out such a system, however, we'd like to get your opinion. Do you read the reviews in Array as they currently stand? Do you think it is a good idea to have an online discussion forum available for each ICMC concert? Would you actually participate in these forums if they existed? Do you think we should dispense with written reviews, or do you think that no amount of online discussion can replace the written review? Would you agree to have your work(s) exist in some form on the ICMA website? Please direct your comments to array.journal@gmail. com. We will take them into account when the board discusses the future direction of Array. We look forward to hearing from you. 